\title{
Relationship between children physical activity, inflammatory mediators and lymphocyte activation: possible impact of social isolation (COVID-19)
}

\author{
Murilo Merlin ${ }^{1,2}$. Heloisa Helena de Oliveira ${ }^{1} \cdot$ Maria Elizabeth Pereira Passos $^{1}$. Cesar Miguel Momesso ${ }^{1}$ \\ Laiane Cristina dos Santos de Oliveira ${ }^{1}$. Juliana Exel Santana ${ }^{3}$. Adriana C. Levada-Pires ${ }^{1} \cdot$ Elaine Hatanaka ${ }^{1}$. \\ Sandro Massao-Hirabara ${ }^{1} \cdot$ Renata Guaré $^{1} \cdot$ Maria Fernanda Cury-Boaventura ${ }^{1} \cdot$ Tania C. Pithon-Curi $^{1}$. \\ Renata Gorjão ${ }^{1}$
}

Received: 30 January 2020 / Accepted: 2 November 2020 / Published online: 23 November 2020

(c) Springer-Verlag Italia S.r.l., part of Springer Nature 2020

\begin{abstract}
Objective Lifestyle and body composition may be simultaneously responsible for immune response modulation. This study aimed to compare plasmatic adipokines concentration and lymphocyte cytokine production in children with different daily steps (DS) range, as well as to discuss the potential negative impact of the social isolation during COVID-19 pandemic in this context. DS can be a useful and low-cost way of monitoring children's health status.

Study design Fifty children were classified into clusters based in DS measured by pedometer: Sedentary Group (DS $=9338 \pm 902$ steps) and Active Group (DS =13,614 \pm 1003 steps). Plasma and lymphocytes were isolated and cultured to evaluate cytokine production.

Results Sedentary group presented lower adiponectin $(7573 \pm 232 \mathrm{pg} / \mathrm{mL})$, higher leptin $(16,250 \pm 1825 \mathrm{pg} / \mathrm{mL})$ plasma concentration, and higher lymphocyte production of IL-17, IFN-gamma, TNF-, IL-2 in relation to active group, suggesting predominance of Th1 response. Otherwise, the active group presented higher lymphocyte supernatant concentration of IL-10 and higher regulatory $\mathrm{T}$ cell (Treg) percentage.

Conclusion These results indicate that lymphocytes of children performing higher DS have an anti-inflammatory profile, especially of Treg. Besides, the prolonged social isolation in children during the COVID-19 pandemic, limiting physical mobility and exercise, reduces DS and increases adiposity, which could impair the immune system function and raise the susceptibility to inflammatory diseases.
\end{abstract}

Keywords Childhood obesity $\cdot$ Physical activity $\cdot$ Inflammation $\cdot$ Adipokines $\cdot$ Social isolation $\cdot$ Mobility reduction

Renata Gorjão

renata.gorjao@cruzeirodosul.edu.br

1 Interdisciplinary Post-Graduate Program in Health Sciences, Institute of Physical Activity Sciences and Sports, Cruzeiro do Sul University, Rua Galvao Bueno, 868, Liberdade, Sao Paulo, SP 01506-000, Brazil

2 School of Physical Education, University of Campinas, Campinas, Brazil

3 Department of Biomechanics/Kinesiology and Applied Computer Science, University of Vienna, Vienna, Austria

\section{Introduction}

Several studies have investigated the association of physical activity, obesity, and immune system. The World Health Organization (WHO) recommends to children and adolescents at least $60 \mathrm{~min}$ per day of moderate to vigorous physical activity (PA) aiming health promotion and prevention of diseases, including obesity. However, WHO estimates that more than $80 \%$ of adolescents are physically inactive and that 34 million children and adolescents aged between 5 and 19 years old were overweight or obese in 2016. Recent studies have shown that in children and adolescents it was observed a decrease of physical activity levels in the last years in several countries $[1,2]$. 
Nowadays, the wide world is crossing by an unprecedented pandemic coronavirus disease 2019 (COVID-19), which will undoubtedly have a negative impact on the reduction of physical activity and its protective role of the immune system. The World Health Organization has proposed that the crucial strategy to diminish the COVID-19 pandemic impact is social isolating and distancing (WHO, 2020), keeping people at home, and therefore limiting their physical mobility and exercise. Previous studies have indicated that the immune system function is modulated by physical exercise, depending on the intensity and duration of the exercise effort, promoting different adaptations, acutely, and chronically [1]. Although current statistics show an alarming and increasing number of people under physical inactivity and obesity under normal conditions, the great concern that this number will worsen during the quarantine period [2], this proposition is supported by studies that observed weight gain during school vacation periods with a consequent increase in the prevalence of overweight and obesity [3,4].

Obesity deregulates energetic metabolism and hormonal function resulting in a low-grade inflammation [3, 4]. Adipocytes release several adipokines, such as leptin, adiponectin, and resistin, which lead to inflammation and insulin resistance [5]. In response to inflammation, the innate immune system activates naïve $\mathrm{T}$ cells, inducing them to differentiation $[6,7]$. Regulatory $\mathrm{T}$ cells (Tregs) are important in the maintenance of tolerance, prevention of autoimmune disease, and control of inflammation. The correct responsiveness of these cells is import to immune homeostasis. Interleukin (IL)-6 and leptin inhibit regulatory T cells (Treg), and adiponectin induces IL-10 production. Nevertheless, in obese people, the opposite occurs, resulting in a lower production of IL-10 [8]. It is important to consider that obesity is the result of a complex interaction of genetic, environmental, social, hormonal factors in addition to physical activity [4]. Therefore, physical activity can bring a direct effect to overweight and obese children and adolescents, promoting a reduction of inflammation $[9,10]$.

In the last years, pedometer has been widely used in the scientific and practical contexts as a simple and accessible device able to indicate PA levels in different population groups, including children. However, there is no consensus on the most appropriate range of daily steps to indicate physically active children. Researchers have to aim to establish a relationship between the number of daily steps and physical activity level [11-15] and with anthropometric parameters $[16,17]$.

Herein, we hypothesized that the clusters composed of children who perform different mean of daily steps have different plasmatic concentrations of leptin and adiponectin and altered inflammatory responses through cytokines produced by lymphocytes. This study aimed was to compare leptin and adiponectin plasmatic concentration and cytokine production by lymphocytes in children with different daily steps range, as well as to discuss the potential negative impact of the social isolation during COVID-19 pandemic in this context.

\section{Methods}

\section{Sample}

The experimental procedures were conducted according to the Declaration of Helsinki after approval from the Ethics Committee of Cruzeiro do Sul University (Protocol CU/ UCS-169/2012). All legal representatives were informed about the research and provided written consent before children being enrolled in the study. Fifty children participated in this study, composed of twenty-nine males and twentyone females, all classified as pre-pubertal according to Tanner board proposed by Matsudo \& Matsudo [18]. Children who presented a previous diagnosis of diseases (such as infections in general, leukemia, asthma, and autoimmune diseases) or characteristics that could interfere in the results (use of medicines chronically) were not included.

\section{The determining mean of daily steps}

The number of daily steps (DS) was determined using Digiwalker-Yamax pedometers SW 200 [19]. Children were evaluated for seven consecutive days and recorded the number of daily steps. It calculated the mean over this period. The children and responsible respective legal guardians were instructed about the correct use of the pedometer, and only the children who fulfilled all the guidelines were considered.

\section{Determination of anthropometric parameters}

Body mass index (BMI) was calculated using the formula: $\mathrm{BMI}=$ Body Weight $(\mathrm{Kg}) /$ height $^{2}(\mathrm{~m})$. For the nutritional profile, it was used benchmarks in $z$ score based on BMI curves for boys and girls, proposed by the WHO in 2007 [20]. Body composition (percentage of fat, fat body mass, and lean body mass) was estimated using the bioimpedance analysis (BIA). The BIA measurement was performed on the right side of the body, with the child lying supine on a non-conductive surface in a room with a normal temperature $\left(\sim 22{ }^{\circ} \mathrm{C}\right)$, and the protocol followed the instruction manual.

\section{Blood collection}

After overnight fasting ( $8 \mathrm{~h})$, blood was collected from the antecubital vein into tubes containing ethylenediaminetetraacetic acid (EDTA, $1 \mathrm{mg} / \mathrm{mL}$ ). After, the blood was 
centrifuged at $4{ }^{\circ} \mathrm{C}, 400 \mathrm{~g}$, for $10 \mathrm{~min}$. Plasma samples were separated and frozen $\left(-80^{\circ} \mathrm{C}\right)$ for further assays.

\section{Lymphocyte isolation}

Lymphocytes were isolated from peripheral blood. After plasma separation, blood was diluted in phosphate-buffered saline (PBS, pH 7.4) (1:1), suspended in Histopaque-1077 (Sigma Chemical Co., St. Louis, MO, EUA), and centrifuged for $30 \mathrm{~min}, 400 \mathrm{~g}$, at room temperature. Peripheral blood mononuclear cells (PBMC; a mixture of monocytes and lymphocytes) were collected from the interphase. Remnant erythrocytes were lysed with $150 \mathrm{mM} \mathrm{NH}_{4} \mathrm{CI}, 10 \mathrm{mM}$ $\mathrm{NaHCO}_{3}$, and $0.1 \mathrm{mM}$ EDTA, at a pH of 7.4. PBMCs were washed once with PBS and maintained in RPMI-1640 medium to allow adherence of the monocytes to the plates for further isolation of pure lymphocyte population from the supernatant (approximately $98 \%$ lymphocytes). The number of lymphocytes was determined using a Neubauer chamber under an optical microscope (Nikon, Melville, NY).

\section{Primary culture of human lymphocytes}

The isolated lymphocytes were cultured in RPMI-1640 supplemented with $10 \%$ fetal bovine serum-containing antibiotics (10,000 $\mathrm{U}$ penicillin and $10 \mathrm{mg} / \mathrm{L}$ streptomycin medium) at the concentration of $1 \times 10^{6}$ cells per $\mathrm{mL}$. At the beginning of the culture, human lymphocytes were stimulated with concanavalin A $(5 \mu \mathrm{g} / \mathrm{mL})(\mathrm{ConA})$ at $37{ }^{\circ} \mathrm{C}$ and $95 \%$ air $/ 5 \% \mathrm{CO}_{2}$ atmosphere for $24 \mathrm{~h}$. ConA is a mitogenic agent of $\mathrm{T}$ lymphocytes that binds to glycoproteins complexed to $\mathrm{T}$ cell receptor (TCR), promoting the activation of these cells. After this time, the cell suspension was centrifuged ( $400 \mathrm{~g}$ for $10 \mathrm{~min}$ ), and the supernatant was collected and stored at $-70{ }^{\circ} \mathrm{C}$.

\section{Determination of cytokines in the supernatant}

TNF-alpha, IL-17, IL-4, IL-6, IL-2, IL-10, and IFNgamma concentrations in the supernatant were determined by Cytometric Bead Array (CBA), using the $\mathrm{BD}^{\mathrm{TM}} \mathrm{CBA}$ Th1Th2Th17 Human Cytokine Kit (BD Biosciences) and a BD Accuri flow cytometer. Briefly, $25 \mu \mathrm{L}$ of particles containing different fluorescent beads and covered with specific antibodies for the cytokines were added to $25 \mu \mathrm{L}$ of diluted culture supernatant and incubated for $1 \mathrm{~h}$, at room temperature in the dark. Afterward, $25 \mu \mathrm{L}$ of the secondary antibody conjugated to a fluorochrome was added to the suspension, followed by the incubated for $2-\mathrm{h}$, at room temperature. At the same time, the standards for each cytokine were similarly used in the absence of the samples. The particles were washed to remove the unbound antibodies, suspended in washing buffer, and analyzed using the $B D$ Accuri (BD Biosciences). The acquisition was made in BD-Accuri C6 Software, and the cytokine concentrations determined using the FCAP Software v.3.0 (BD, Biosciences). The limit of detection was $0.1 \mathrm{pg} / \mathrm{mL}$ for IL-2, $0.03 \mathrm{pg} / \mathrm{mL}$ for IL-4, $1.4 \mathrm{pg} / \mathrm{mL}$ for IL-6, $0.5 \mathrm{pg} / \mathrm{mL}$ for IFN-gamma, $0.9 \mathrm{pg} / \mathrm{mL}$ for TNFalpha, $0.8 \mathrm{pg} / \mathrm{mL}$ for IL-17A, and $16.8 \mathrm{pg} / \mathrm{mL}$ for IL-10.

\section{Determination of $\mathrm{T}$ regulatory cells (Treg)}

Lymphocytes were suspended in PBS and labeled with FITC-conjugated anti-CD4 and APC-anti-CD25 (1:50) (Becton Dickinson, San Juan, CA). Cells were incubated for $30 \mathrm{~min}$ at room temperature in the dark. Negative control cells were incubated with isotype-matched nonreactive IgG1 antibody. Thereafter, lymphocytes were washed with PBS and analyzed using a BDAccuri flow cytometer (Becton Dickinson, San Juan, CA). Twenty thousand events were analyzed per experiment. Fluorescence from cells presenting FITC was evaluated using Diva software (Becton Dickinson). The percentage of Treg cells was determined by the evaluation of $\mathrm{CD} 4^{+}, \mathrm{CD} 25^{+}$, and Foxp $3^{+}$-positive cells. Intranuclear staining of Foxp3 was performed after fixation and permeabilization, according to the manufacturer's protocol, and subsequently incubated with the specific antibody (Becton Dickinson).

\section{Adiponectin and leptin plasma concentration}

Plasma levels of adiponectin and leptin were determined by the ELISA method using the Kit Human Total Adiponectin/ Arcp30 Kit (R and D Systems) and Human Leptin Kit ( $R$ and D Systems) according to manufacturer's instructions.

\section{Statistical analysis}

A two-step cluster based in Euclidean distance and Schwartz's Bayesian criterion was used to classify the sample into the different groups according to the mean of daily steps. It was used Kolmogorov-Smirnov test with the correction of the Lilliefors test to verify the normality of the sample. The null hypothesis for normality was rejected for all analyzed variables. Data are presented as the mean \pm standard deviation for differences between groups and were analyzed by the nonparametric test, unpaired $T$ test (Kolmogorov-Smirnov). Spearman was used for correlation analysis. Statistical significance was set at 0.05 , and the statistical analysis was carried in IBM SPSS Statistics for Windows (Armonk, NY: IBM Corp). 


\section{Results}

The children were classified into two clusters based in the mean of daily steps (DS), where the cluster 1 (Sedentary Group) was characterized by lower mean of DS (9338 \pm 902) and cluster 2 (Active Group) by highest mean of DS $(13,614 \pm 1003)$. The silhouette measurement of cohesion and separation pointed to good cluster quality (between 0.5 and 1.0) to a used method (two-steps cluster). Table 1 shows the means \pm standard deviation for the daily steps, age, and anthropometric parameters (body mass, height, body mass index, fat percentage) for the whole sample and the two groups.

Based on BMI, $100 \%$ of overweight $(n=8)$ and obese $(n=9)$ children were allocated in the sedentary group, and $100 \%$ of the eutrophic children $(n=33)$ were allocated in the active group. Additionally, all anthropometric parameters evaluated were significantly greater to the sedentary group compared to the active group. This tendency was confirmed by correlation analysis, a moderate inverse correlation

Table 1 Anthropometric data, body composition, and age from children separated according to daily step count

\begin{tabular}{lcc}
\hline & $\begin{array}{l}\text { Sedentary group } \\
(n=17)\end{array}$ & Active group $(n=33)$ \\
\hline Daily steps & $9,338 \pm 902$ & $13,614 \pm 1,003^{*}$ \\
Age (years) & $9.00 \pm 1.96$ & $7.54 \pm 1.70^{*}$ \\
Body mass $(\mathrm{Kg})$ & $44.81 \pm 13.15$ & $25.41 \pm 5.78^{*}$ \\
Height $(\mathrm{m})$ & $1.37 \pm 0.12$ & $1.26 \pm 0.11^{*}$ \\
BMI $\left(\mathrm{Kg} / \mathrm{m}^{2}\right)$ & $22.98 \pm 3.08$ & $15.83 \pm 1.54^{*}$ \\
Fat percentage (BIA) & $30.22 \pm 0.99$ & $18.17 \pm 1.07^{*}$ \\
\hline
\end{tabular}

Mean \pm standard deviation

$B M I$ body mass index, $B I A$ bioimpedance

${ }^{*} P<0.05$ vs. group 1
( $r=-0.60, p<0.0001)$ was observed between mean of DS and BMI (Fig. 1a) and between mean of DS and body fat $(r=-0.48, p=0.0004)$ (Fig. 1b).

\section{Analysis of adiponectin and leptin plasmatic concentration}

We found differences for the concentrations of adiponectin (Fig. 2a) and leptin (Fig. 2b) between sedentary and active children. Sedentary group presented lower concentrations of adiponectin $(7573 \pm 232 \mathrm{pg} / \mathrm{mL})$ when compared to active group $(9995 \pm 161 \mathrm{pg} / \mathrm{mL})$. Leptin was higher for sedentary group $(16,250 \pm 1825 \mathrm{pg} / \mathrm{mL})$ compared to active group $(7816 \pm 721 \mathrm{pg} / \mathrm{mL})$.

These differences were reinforced when the total sample adiponectin plasma concentration and DS showed moderate correlation $(r=0.61, p<0.0001)$ between adiponectin and DS (Fig. 3a) and moderate inverse correlation $(r=-0.52$, $p<0.0001)$ between leptin plasma concentration and mean of DS (Fig. 3b).

\section{Analysis of regulatory T cells (Treg)}

Comparison of Treg cell percentage of children separated in the cluster according to the mean of daily steps demonstrated that cluster $1(2.0 \pm 0.3 \mathrm{pg} / \mathrm{ml})$ shows lower Treg cells percentage than cluster $2(8.0 \pm 0.2 \mathrm{pg} / \mathrm{ml})$ (Fig. 4). For the total sample, a strong positive correlation $(r=0.77, p<0.0001)$ was found between plasma concentration of Treg cell and mean of DS, demonstrating that as the daily amount of steps increases, Treg cell population also increases (Fig. 5).

\section{Analysis of cytokine concentration in cell supernatant}

Concerning plasma cytokines analysis, no differences were found between the clusters (data not shown). However,
Fig. 1 a Correlation between BMI $\left(\mathrm{Kg} / \mathrm{m}^{2}\right)$ and mean of daily steps for the total sample $(n=50)$. The correlation analysis $(r=-0.59 ; p<0.0001)$ indicates a moderate inverse correlation. b Correlation between percentage of fat (\%) and mean of daily steps for the total sample $(n=50)$. Correlation analysis $(r=-0.48$, $p=0.0004)$ indicates moderate inverse correlation
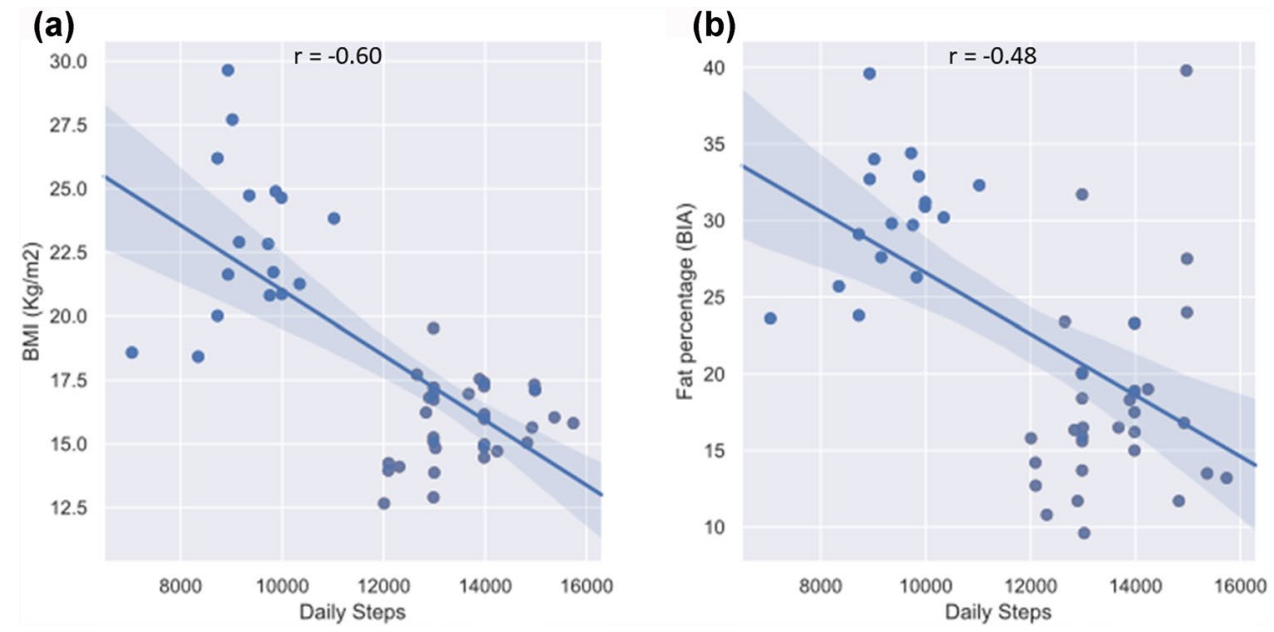


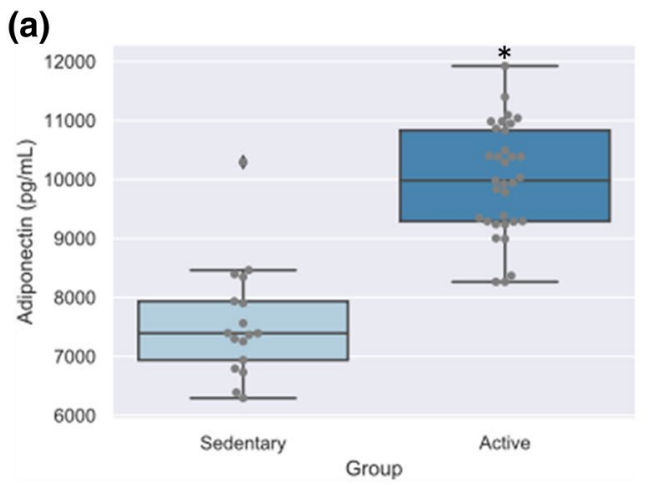

Fig. 2 Comparison (pg/mL) of adiponectin (a) and leptin (b) plasmatic concentration between sedentary and active groups. The plasma concentrations of leptin and adiponectin were determined using an (b)

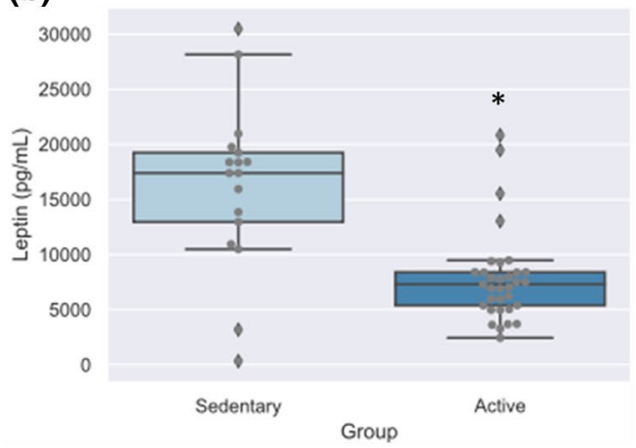

Enzyme-linked immunosorbent assay (ELISA) method. The values presented are the mean \pm standard error of mean $\left({ }^{*} p<0.0001\right.$ versus sedentary group)
Fig. 3 a Correlation between plasma levels of adiponectin $(\mathrm{pg} / \mathrm{ml})$ and number of daily steps for the 50 children evaluated. Values of $r=0.61$ and $p<0.0001$ were found, indicating a moderate correlation between mean of daily steps and adiponectin plasma levels. $\mathbf{b}$ Spearman correlation between plasma levels of leptin $(\mathrm{pg} / \mathrm{ml})$ and the mean of daily steps for the 50 children evaluated. Values of $r=-0.52$ and $p<0.0001$ were found, indicating a moderate inverse correlation between number of daily steps and plasma leptin values
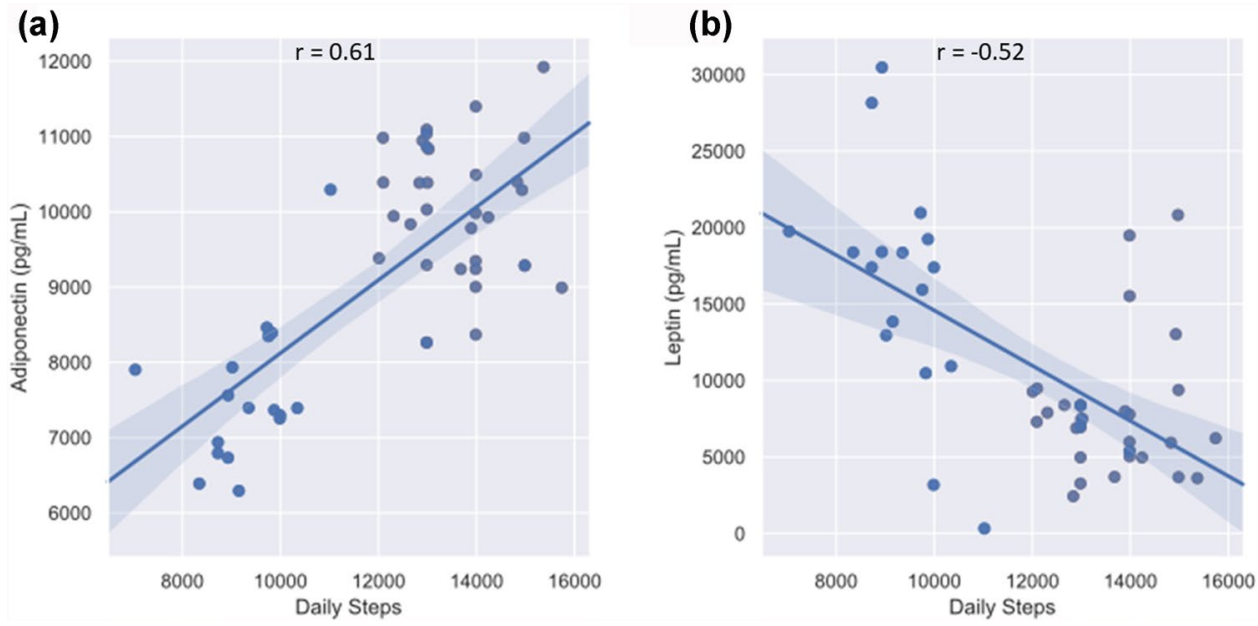

it was found differences between sedentary and active group by lymphocytes in the presence of ConA. Sedentary group presented higher lymphocyte production of IL-17 $(89,820 \pm 29,500 \mathrm{pg} / \mathrm{mL})$, IFN-gamma $(18,010 \pm 2013 \mathrm{pg} /$ $\mathrm{mL})$, TNF-alpha ( $1169 \pm 220 \mathrm{pg} / \mathrm{mL}), \mathrm{IL}-2(292 \pm 72 \mathrm{pg} / \mathrm{mL})$ in relation to active group of IL-17 $(49,840 \pm 16,270 \mathrm{pg} / \mathrm{mL})$, IFN-gamma (1643 $\pm 178 \mathrm{pg} / \mathrm{mL})$, TNF-alpha $(265 \pm 36 \mathrm{pg} /$ $\mathrm{mL}), \mathrm{IL}-2(27 \pm 3 \mathrm{pg} / \mathrm{mL})$, suggesting predominance of Th1 response. Otherwise, the active group presented higher lymphocyte supernatant concentration of IL-10 $(3369 \pm 775 \mathrm{pg} /$ $\mathrm{mL})$ that sedentary group $(426 \pm 165 \mathrm{pg} / \mathrm{mL})$ For IL-4 and IL-6 concentrations, no significant differences were observed.

For the total sample analysis, correlations were found between cytokine concentrations in the lymphocyte supernatant and DS, with a moderate inverse correlation for IL-17 $(r=-0.55, p<0.0001)$, IFN-gamma $(r=-0.68$, $p<0.0001)$, TNF-alpha $(r=-0.46, p=0.0009)$, and IL-2 $(r=-0.62, p=0.0186)$, and moderate correlation for IL-10 $(r=0.48, p<0.005)$.

\section{Discussion}

This is the first study to associate serum adipokynes/ cytokines, lymphocyte activation parameters from children with daily steps. According to our data, daily steps can be a useful noninvasive and low-cost way of monitoring children's health status. Daily steps performance and physical activity levels are correlated [12, 21, 22]. A compliance of 12,000 steps as a threshold for achieving the WHO recommendations for physical activity [23]. In this study, the cluster analysis results allowed the definition of these two different groups as function of their lower (sedentary) or higher (active) level of physical activity grounded on the WHO recommendations.

Children's physical activity levels were distributed in two groups, based on the daily steps performed per day in a typical 7-day week. One of the groups showed limit values between 7039 and 11,023 daily steps, while the other showed daily steps limits between 12,009 and 15,739. 


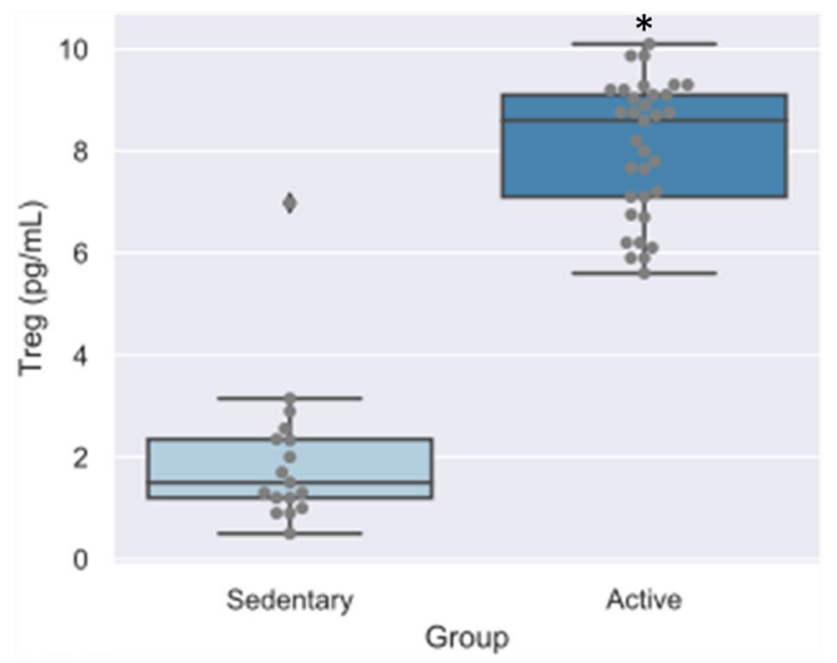

Fig. 4 Comparison of $\mathrm{T}$ regulatory cells percentage of children separated in cluster according to the mean of daily steps. Cells were pelleted and labeled with FITC-conjugated anti-CD4, APCconjugated anti-CD25, and PE-conjugated anti-Foxp3 and analyzed by flow cytometry. The values are presented as the mean \pm S.E.M. ${ }^{*} p<0.0001$ vs. cluster 1

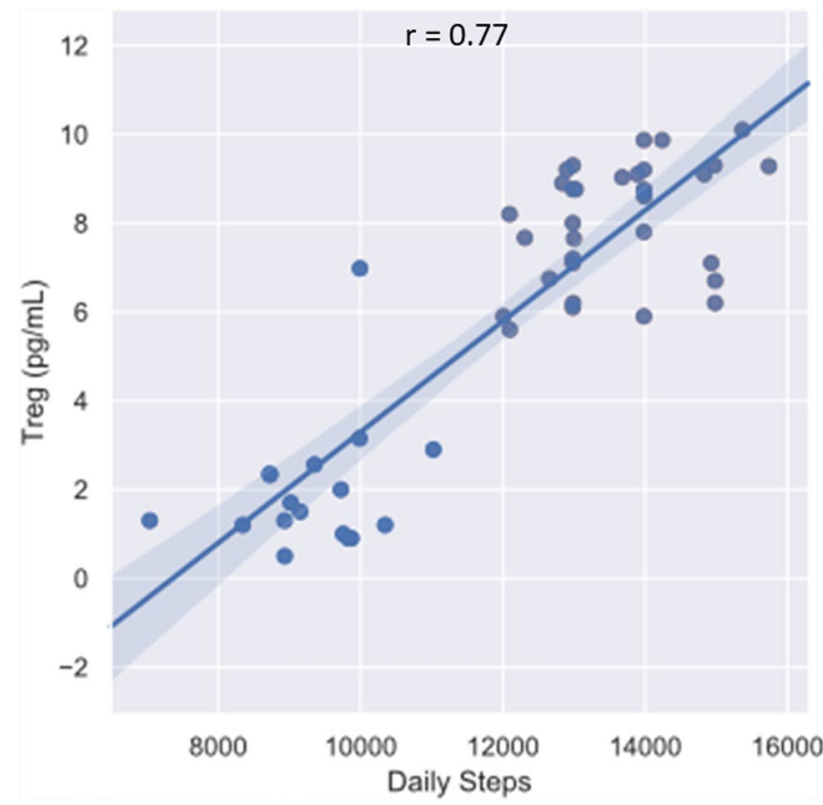

Fig. 5 Correlation analysis between Treg cells and the mean of daily steps for the 50 children evaluated. Cells were pelleted and labeled with FITC-conjugated anti-CD4, APC-conjugated anti-CD25, and PE-conjugated anti-Foxp3 and analyzed by flow cytometry. Values of $r=0.77, p<0.0001$ indicating a strong correlation between mean of daily steps and Treg cells

According to cluster division, $100 \%$ of overweight and obese children were allocated in the cluster $1-100 \%$ of the eutrophic children were allocated in cluster 2 . Also, we found higher body fat in cluster 1 compared to cluster 2 and an inverse correlation of daily steps in the total sample with body fat and BMI corroborating with previous data $[16,17]$.

Another important fact observed in the population studied is that children from cluster 1 presented a lower concentration of the adiponectin and higher of leptin in relation to children from cluster 2 . We also found a positive correlation between mean of DS and adiponectin and negative correlation with leptin concentration. The increase of leptin concomitant with adipose tissue has been widely reported in the literature $[5,24,25]$. However, there is still a gap to be explored between the influence of physical activity on adipokines production, especially about adiponectin and leptin. A previous meta-analysis indicated an association of exercise with increased adiponectin levels in more extended duration exercise programs, through body fat reduction [26]. The present study findings corroborate to this meta-analysis, even though we focused on how the levels of physical activity (PA), defined by DS, would affect these parameters.

We also investigated how different levels of PA could interfere in the cytokine production by lymphocytes from children analyzed in this study. Regarding plasma levels, we did not find any significant difference between the groups for any of the cytokines determined. When lymphocytes were stimulated with ConA, it was found a significant positive difference between the sedentary and active groups for IL-17, INF-gamma, TNF-alpha, IL-10, and IL-2. This relationship is even more evident when we observe a negative correlation between the concentration of IL-17, IFN-gamma, TNFalpha, and IL-2 with daily steps. INF-gamma and TNF-alpha are cytokines with inflammatory characteristics secreted by Th1 cells [27]. Besides that, it has been reported that IL-2, as well as other cytokines, such as INF-gamma and TNFalpha, are elevated in obese individuals [28], which presents low levels of PA. On the other hand, only IL-10 was higher in lymphocytes supernatant for the active group. IL-10 is related to anti-inflammatory response and promotes the differentiation of Treg cells [29]. Its expression is also stimulated for adiponectin [30].

Treg cell percentage was also higher for the active group and presented a higher positive correlation with DS. Treg cells are an anti-inflammatory $\mathrm{T}$ cell subtype with a unique phenotype controlling proliferation of effector $\mathrm{T}$ cells [3]. The present findings of Tregs show the important relationship between higher PA level and Treg cell concentration. Similar results previously found an association between lifestyle factors, such as PA, with immune system homeostasis and shift the balance of the immune system toward a more anti-inflammatory state by increasing Treg cells [31]. Although there are reports of a lower percentage of Treg cells in overweight children when compared with eutrophic, there was no evidence on the effect of physical exercise or PA levels on the Treg cells [32]. Thus, the present study 


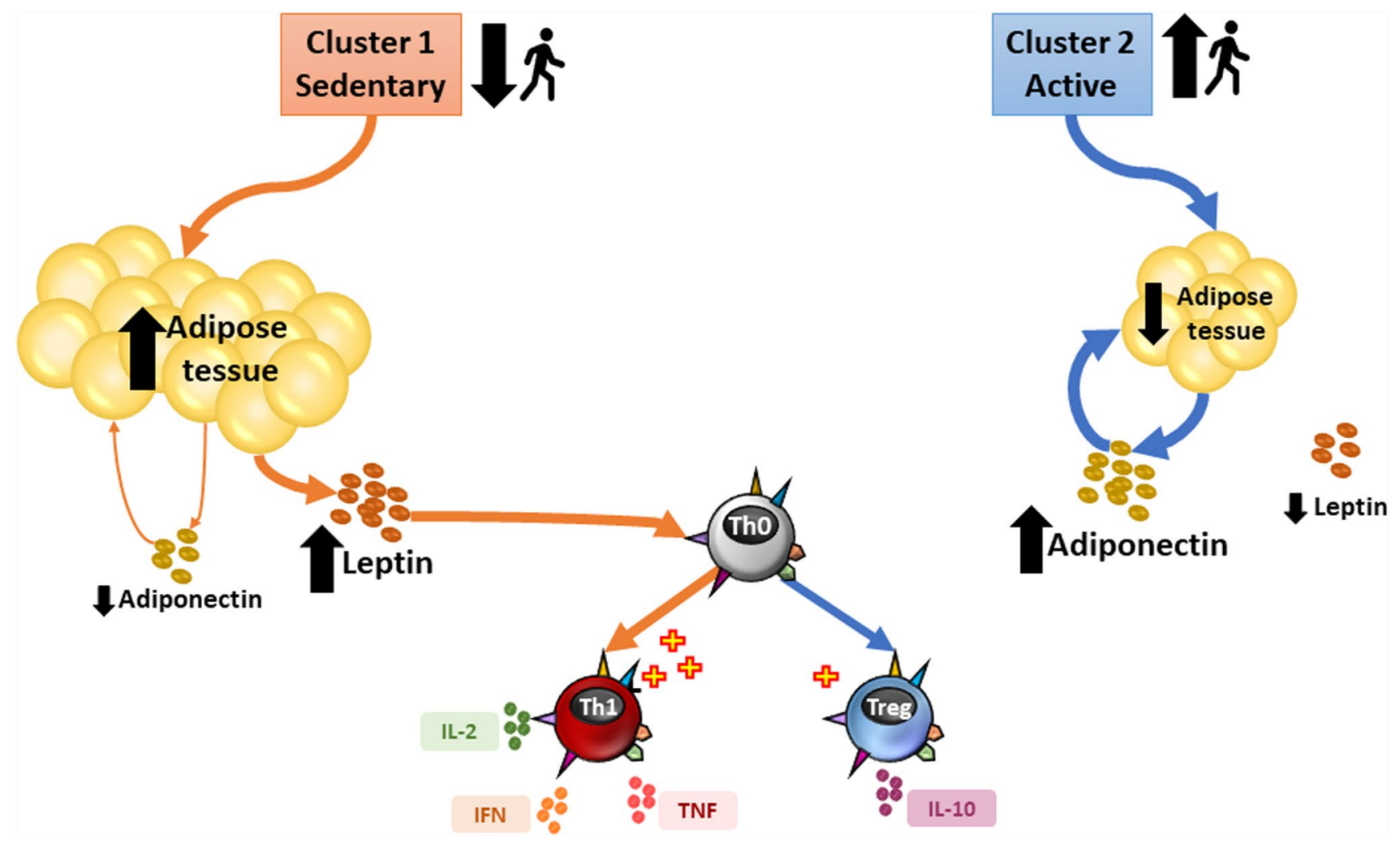

Fig. 6 Summary of the results involving analysis of relation between children daily steps, adipokines and lymphocyte response

brings novel information about the interaction between PA and the immune system.

The results about the production of inflammatory mediators secreted by lymphocytes or adipokines according to different levels of PA are also new information related to this issue. The sedentary group presented lower adiponectin and higher leptin plasmatic concentration, as well as higher lymphocyte supernatant concentration of IL-17, IFN-gamma, TNF-alpha, and IL-2. It suggests that children less physically active tend to present predominance of Th1 response for lymphocyte differentiation. The leptin produced by adipose tissue may contribute to the higher production of IFN-gamma and TNF-alpha by lymphocytes. Lymphocytes have receptors for leptin that favor their proliferation [33]. These findings partially confirm previous results about the significant correlation between leptin levels and IFN-gamma levels in obese asthmatic children, suggesting that leptin may mediate the increase of this cytokine, contributing to the Th1 response [34]. On the other hand, the active group presented higher adiponectin and lowered leptin plasmatic concentration, higher lymphocyte supernatant concentration of IL-10, and higher Treg cells concentration. In this case, the results suggest that children physically active tend to present anti-inflammatory response, especially of regulatory $\mathrm{T}$ cells. Nevertheless, it is important to highlight that level of PA and anthropometrics may simultaneously promote important immune responses, once the sedentary group presented mean of BMI value referent to overweight and obese children. In contrast, the active group showed BMI mean rated for eutrophic children. A summary of the results is represented in Fig. 6.

Considering our results found with the current scenario of the COVID-19 pandemic, while children are under social isolation [35] and consequent reduced physical mobility and exercise, we have an alarming situation. Children are further precluded from having physical activities, including those practiced in school and extracurricular environments, significantly reducing the daily physical activity level. Also, prolonged isolation of children at home could promote increased sedentary behavior and decreased regular physical activity and energy expenditure. Children could spend a long time sitting or lying down for sedentary activities, including playing games, watching television, and using mobile devices [36]. All these factors will be accentuated during a prolonged period of quarantine, exacerbating the problems caused by physical inactivity, such as those observed in the sedentary group, including overweight, obesity, and related diseases. Therefore, it is important to establish alternative ways to increase daily step counts during this period. As mentioned by [37] there are numerous exercise programs planned for practice with limited gym equipment and these 
programs could be adapted by schools in the home lesson strategies.

In conclusion, children present mainly two different levels of PA based on daily steps mean, and these differences reflect on their body composition and inflammatory responses. The sedentary group children characterized by lower PA level presented higher BMI, body fat, and increased Th1 cells that and can be modulated by the higher production of leptin. The active group characterized by higher levels of PA have lower BMI, body fat, as well as higher Treg cell differentiation. These results suggest that DS can be a useful and low-cost way of monitoring children's health status. Besides, we discuss the adverse effects of the prolonged social isolating in children during the COVID-19 pandemic in reducing physical mobility and exercise, increasing sedentary behavior, and elevating the adiposity, which could impair the immune system function and raise the susceptibility to infectious diseases.

Acknowledgements We grateful Paula Bresciani Martins Andrade, and Rebeca dos Passos Costa for technical assistance. Cruzeiro do Sul University, Curtin School of Pharmacy and Biomedical Sciences and CHIRI (Curtin University), São Paulo Research Foundation (FAPESP, Process No.: 2018/07283-1), Coordination for the Improvement of Higher Level Personnel (CAPES), and National Council for Scientific and Technological Development (CNPq) supported this study.

\section{Compliance with ethical standards}

Conflict of interest The authors declare no conflict interest.

Ethical approval The experimental procedures were conducted according to the Declaration of Helsinki after approval from the Ethics Committee of Cruzeiro do Sul University (Protocol CU/UCS-169/2012).

Informed consent All legal representatives were informed about the research and provided written consent before children being enrolled in the study.

\section{References}

1. Raustorp A, Science S (2017) Comparisons of pedometer-determined weekday physical activity among Swedish school children and adolescents in 2000 and 2017 showed the highest reductions in adolescents. Acta Pediatr 108(7):1303-1310. https://doi. org/10.1111/apa.14678

2. Sato H, Inoue S, Fukushima N, Kikuchi H, Takamiya T, Tudorlocke C (2018) Lower youth steps / day values observed at both high and low population density areas : a cross-sectional study in metropolitan Tokyo. BMC Public Health 1132(18):1-14. https:// doi.org/10.1186/s12889-018-6028-y

3. Apostolopoulos V, de Courten MPJ, Stojanovska L, Blatch GL, Tangalakis K, de Courten B (2016) The complex immunological and inflammatory network of adipose tissue in obesity. Mol Nutr Food Res 60(1):43-57. https://doi.org/10.1002/mnfr.201500272

4. Gurnani M, Birken C, Hamilton J (2015) Childhood obesity causes, consequences, and management. Pediatr Clin North Am 62(4):821-840. https://doi.org/10.1016/j.pcl.2015.04.001
5. Foschini D, dos Santos RVT, Prado WL, de Piano A, Lofrano MC, Martins AC, Dâmaso AR (2008) Platelet and leptin in obese adolescents. J Pediatr 84(6):516-521. https://doi.org/10.2223/ JPED. 1845

6. Dominguez-Villar M, Baecher-Allan CM, Hafler DA (2011) Identification of $\mathrm{T}$ helper type 1-like, Foxp3+ regulatory $\mathrm{T}$ cells in human autoimmune disease. Nat Med 17(6):673-675. https://doi. org/10.1038/nm.2389

7. Snyder-Cappione J, Nikolajczyk B (2013) When diet and exercise are not enough, think immunomodulation. Mol Aspects Med 34(1):30-38. https://doi.org/10.1016/j.mam.2012.10.003

8. Linneberg A (2007) The link between the epidemics of obesity and allergic diseases : does obesity induce decreased immune tolerance? Allergy 1987(1):1205-1213. https://doi.org/10.111 1/j.1398-9995.2007.01506.x

9. Izadpanah A, Barnard RJ, Almeda AJE, Baldwin GC, Bridges SA, Shellman ER et al (2012) A short-term diet and exercise intervention ameliorates inflammation and markers of metabolic health in overweight/obese children. Am J Physiol Endocrinol Metab 303(4):E542-E550. https://doi.org/10.1152/ajpendo.00190.2012

10. Vasconcellos F, Seabra A, Katzmarzyk P, Kraemer-Aguiar L, Bouskela E, Farinatti P (2014) Physical activity in overweight and obese adolescents: systematic review of the effects on physical fitness components and cardiovascular risk factors. Sports Med 44:1139-1152. https://doi.org/10.1007/s40279-014-0193-7

11. Alinia P, Cain C, Fallahzadeh R, Shahrokni A, Cook DJ, Ghasemzadeh H (2017) How accurate is your activity tracker? A comparative study of step counts in low-intensity physical activities. J Med Internet Res 5(8):1-10. https://doi.org/10.2196/mheal th. 6321

12. Fukushima N, Inoue S, Hikihara Y, Kikuchi H, Sato H, TudorLocke $\mathrm{C}$ et al (2016) Pedometer-determined physical activity among youth in the Tokyo Metropolitan area: a cross-sectional study. BMC Pub Health 16(1):1104. https://doi.org/10.1186/s1288 9-016-3775-5

13. Rush E, Coppinger T, Obolonkin V, Hinckson E, McGrath L, McLennan S et al (2015) Use of pedometers to identify less active children and time spent in moderate to vigorous physical activity in the school setting. J Sci Med Sport 15(3):226-230. https://doi. org/10.1016/j.jsams.2011.11.001

14. Tudor-locke C, Craig CL, Beets MW, Belton S, Cardon GM, Duncan $S$ et al (2011) How many steps/day are enough? for children and adolescents. Int J Behav Nutr Phys Act 8(1):78. https://doi. org/10.1186/1479-5868-8-78

15. Tudor-Locke C, Craig CL, Thyfault JP, Spence JC (2013) A stepdefined sedentary lifestyle index: $<5000$ steps/day. Appl Physiol Nutr Metab 38:100-114. https://doi.org/10.1139/apnm-2012-0235

16. Collings PJ, Brage S, Ridgway CL, Harvey NC, Godfrey KM, Inskip HM et al (2013) Physical activity intensity, sedentary time, and body composition in preschoolers. Am J Clin Nutr 97(5):1020-1028. https://doi.org/10.3945/ajcn.112.045088

17. Miguel-Berges M, Reilly J, Aznar L, Jimenez-Pavon D (2009) Associations between objectively measured habitual physical activity and adiposity in children and adolescents: systematic review. Int J Pediatr Obes 5(1):3-18. https://doi.org/10.1097/ JSM.0000000000000419

18. Matsudo SMM, Matsudo VKR (1994) Self-assessment and physician assessment of sexual maturation in Brazilian boys and girls: concordance and reproducibility. Am J Hum Biol 6(4):451-455. https://doi.org/10.1002/ajhb.1310060406

19. Louie L, Eston RG, Rowlands AV, Keung K, Ingledew DK, Fu FH (1999) Validity of heart rate, pedsmetry, and accelerometry for estimating the energy cost of activity in Hong Kong Chinese boys. Pediatr Exerc Sci 11:229-239

20. De Onis M, Onyango AW, Borghi E, Siyam A, Nishida C, Siekmann J (2007) Development of a WHO growth reference for 
school-aged children and adolescents. Bull World Health Organ 85(10):812-819. https://doi.org/10.2471/BLT.07.043497

21. Evenson KR, Wen F, Hales D, Herring AH (2016) National youth sedentary behavior and physical activity daily patterns using latent class analysis applied to accelerometry. Int J Behav Nutr Phys Act 13(1):1-14. https://doi.org/10.1186/s12966-016-0382-x

22. Park J, Ishikawa-Takata K, Lee S, Kim E, Lim K, Kim H et al (2016) Association between daily step counts and physical activity level among Korean elementary school children. J Exerc Nutr Biochem 20(3):51-55. https://doi.org/10.20463/jenb.2016.09.20.3.8

23. Colley RC, Janssen I, Tremblay MS (2012) Daily step target to measure adherence to physical activity guidelines in children. Med Sci Sports Exerc 44(5):977-982. https://doi.org/10.1249/ MSS.0b013e31823f23b1

24. Arslan N, Erdur B, Aydin A (2010) Hormones and cytokines in childhood obesity. Indian Pediatr 47(10):829-839. https://doi. org/10.1007/s13312-010-0142-y

25. Yoshinaga M, Sameshima K, Ihnaka Yq, Wada A, Hashiguchi J, Taliara H, Kono A (2008) Adipokines and the prediction of the accumulation of cardiovascular risk factors or the presence of metabolic syndrome in elementary school children. Circ J 72(11):1874-1878. https://doi.org/10.1253/circj.CJ-08-0180

26. García-Hermoso A, Ceballos-Ceballos R, Poblete-Aro C, Hackney A, Mota J, Ramírez-Vélez R (2017) Exercise, adipokines and pediatric obesity: a meta-analysis of randomized controlled trials. Int J Obes 41:475-482. https://doi.org/10.1038/ijo.2016.230

27. Mclaughlin T, Ackerman SE, Shen L, Engleman E (2017) Role of innate and adaptive immunity in obesity-associated metabolic disease. J Clin Invest 127(1):5-13. https://doi.org/10.1172/JCI88 876

28. Chatzigeorgiou A, Karalis KP, Bornstein SR, Chavakis T (2012) Lymphocytes in obesity-related adipose tissue inflammation. Diabetologia 55(10):2583-2592. https://doi.org/10.1007/s0012 5-012-2607-0

29. Moore KW, de Waal MR, Coffman RL, O'Garra A (2001) Interleukin -10 and the I Nterleukin -10 R Eceptor. Annu Rev Immunol 19(1):683-765. https://doi.org/10.1146/annurev.immun ol.19.1.683
30. Wolf AM, Wolf D, Rumpold H, Enrich B, Tilg H (2004) Adiponectin induces the anti-inflammatory cytokines IL-10 and IL-1RA in human leukocytes. Biochem Biophys Res Commun 323(2):630-635. https://doi.org/10.1016/j.bbrc.2004.08.145

31. Weinhold M, Shimabukuro-Vornhagen A, Franke A, Theurich S, Wahl P, Hallek M et al (2016) Physical exercise modulates the homeostasis of human regulatory T cells. J Allergy Clin Immunol 137(5):1607-1610. https://doi.org/10.1016/j.jaci.2015.10.035

32. Momesso Dos Santos CM, Sato FT, Cury-Boaventura MF, Guirado-Rodrigues SH, Caçula KG, Santos CCG, Gorjão R (2015) Effect of regular circus physical exercises on lymphocytes in overweight children. PLoS ONE 10(3):1-16. https://doi. org/10.1371/journal.pone.0120262

33. Fantuzzi G (2005) Adipose tissue, adipokines, and inflammation. J Allergy Clin Immunol 115(5):911-920. https://doi.org/10.1016/j. jaci.2005.02.023

34. Youssef DM, Elbehidy RM, Shokry DM, Elbehidy EM (2013) The influence of leptin on Th1/Th2 balance in obese children with asthma. J Bras Pneumol 39(5):562-568. https://doi.org/10.1590/ S1806-37132013000500006

35. Chen P, Mao L, Nassis GP, Harmer P, Ainsworth BE, Li F (2020) Coronavirus disease (COVID-19): the need to maintain regular physical activity while taking precautions. J Sport Heal Sci 9(2):103-104. https://doi.org/10.1016/j.jshs.2020.02.001

36. Owen N, Sparling PB, Healy GN, Dunstan DW, Matthews CE (2010) Sedentary behavior: emerging evidence for a new health risk. Mayo Clin Proc 85(12):1138-1141. https://doi.org/10.4065/ mcp.2010.0444

37. Rundle AG, Park Y, Herbstman JB, Kinsey EW, Wang YC (2020) COVID-19-related school closings and risk of weight gain among children. Obes J 28(6):1008-1009. https://doi.org/10.1002/ oby. 22813

Publisher's Note Springer Nature remains neutral with regard to jurisdictional claims in published maps and institutional affiliations. 